\title{
O PENSAMENTO TUTELAR PRESENTE NA EDUCAÇÃO DOS GRUPOS POPULARES NO BRASIL
}

\section{Maria do Carmo Brant de Carvalho}

Resumo: Este artigo trata do pensamento tutelar ainda enraizado na cultura política brasileira que acaba por manter uma educação excludente. Destaca o significado e importância da ação emancipatória.

Palavras-chave: Direito à educação. Problemas sociais. Política educacional. Política (Brasil).

O foco desse artigo é a política de educação no enfrentamento da pobreza e das desigualdades no Brasil.

Há dois fatores que despotencializam a política de educação pública no Brasil. Ou melhor, que reduzem sua eficácia no que tange o combate à pobreza:

1. A tutela, como cultura política que impregna toda a ação do Estado e da sociedade civil. As desigualdades no Brasil são tão grandes e seculares que não atinamos para o nosso comportamento tutelar para com os desiguais.

2. A política de educação não vem se integrando incisivamente à política social nacional. Mantém-se como política setorial independente. Em conseqüência, faz do sistema de ensino básico um sistema fechado e isolado. As escolas, no geral, reproduzem o isolamento e são pouco oxigenadas pelos grandes desafios nacionais, como o enfrentamento da pobreza e das desigualdades - questões onde justamente seu papel é crucial. O chamado fracasso escolar tão noticiado pela mídia tem relação direta com as dificuldades da educação em adequar-se/flexibilizar-se para garantir aprendizagens em contexto de pobreza. 
Nosso projeto educacional não tem se comprometido com a luta pela erradicação da pobreza.

Um projeto educacional voltado a combater pobreza e desigualdades tem sempre uma perspectiva multidimensional e multissetorial. Há uma interdependência entre políticas e serviços do território. Nenhuma política de per si ganha efetividade social. As políticas setoriais estão sufocadas pela tutela. Essa postura tem reduzido as possibilidades de reinventar a política social no país.

10 pensamento tutelar - o que é tutela?

O pensamento tutelar é aquele que subestima as capacidades dos desiguais, capacidades essas referidas a pensar, transitar com autonomia, exercer liberdades. A tutela é filha dileta do assistencialismo, do apadrinhamento, do clientelismo.

O pensamento tutelar está enraizado no fazer público. Está presente nas políticas, programas e serviços de assistência social, educação, saúde, combate à pobreza.

É muito recente na política pública a substituição, por exemplo, das cestas alimentares - exemplo máximo da tutela - por transferências monetárias.

São ainda corriqueiras falas presentes no senso comum que revelam o ranço tutelar e, com ele, o descrédito nas capacidades de escolha dos pobres:

"O pobre não pode receber dinheiro porque irá gastar em pinga..." ou "Não teremos garantia (transferências monetárias) de que saberá bem escolher os alimentos de que necessita".

Mas a tutela não está presente apenas nas doações em espécie. Ela está, sobretudo, no acesso aos serviços e na oferta de oportunidades.

É assim que na unidade básica de saúde ou na escola o pobre não tem a mesma chance de reconhecimento e interlocução.

Era, e ainda é muito comum, ofertarem-se para os pobres serviços pobres. Não há um compromisso dos serviços e da sociedade em geral com o desenvolvimento de suas capacidades substantivas.

Amartya Sen (2000), prêmio Nobel há alguns anos atrás, já formulava essa equação social básica: não há possibilidade de exercemos liberdades substantivas se não tivermos nossas capacidades substantivas desenvolvidas.

Ora, nesse campo é crucial o compromisso da educação e da saúde. É como se a escola e a unidade básica de saúde girassem e girassem o discurso dos direitos de todos mas fossem impotentes para assegurar desenvolvimento de capacidades substantivas dos pobres. 
Essa situação tornou-se intolerável:

(a) Adentramos o século XXI com $9 \%$ de analfabetos absolutos; $31,3 \%$ de pessoas que pouco utilizam a leitura e a escrita em sua vida diária, revelando compreensão mínima de um texto escrito; e somente $26,2 \%$ atingem níveis mais elevados nessas habilidades, usando de forma intensa e diversificada a linguagem escrita, como, por exemplo, lendo jornais regularmente ou usando meios escritos para obter novos conhecimentos (Instituto Brasileiro de Geografia e Estatística [IBGE], 2000; Indicador Nacional de Analfabetismo Funcional [INAF], 2001) ${ }^{1}$ Essa é a face mais contundente da pouca eficiência da escola, uma vez que tais habilidades são, ao mesmo tempo, um dos principais objetivos do ensino fundamental e conhecimento de base para a aprendizagem em todas as áreas do currículo escolar.

(b) Paralelamente, mais de $80 \%$ dos alunos que freqüentaram a $4^{a}$ série do ensino fundamental não se apropriaram das habilidades esperadas para essa etapa escolar (SAEB, 2001).

(c) De cada 100 crianças matriculadas na $1^{\text {a }}$ série do ensino fundamental, apenas 54 concluem a $8^{\text {a }}$ série. Entre jovens de 15 a 17 anos, apenas $44 \%$ cursam o ensino médio. Na zona rural esse índice cai para $22 \%$.

A tutela igualmente está presente no trato de alguns públicos e programas sociais. Meninos e meninas que vivem na rua continuam se mantendo na rua sem propostas ambiciosas de alteração desse cenário. Ou, ainda, o programa PETI (Programa Nacional de Erradicação do TrabaIho Infantil), que após 10 anos de implementação apresenta resultados pífios na freqüência, permanência e sucesso escolar de crianças e adolescentes retirados do trabalho precoce. Ou mesmo, as famílias do Programa Bolsa Família, cuja condicionalidade - educação dos filhos - se mantém pouco viabilizada.

A tutela é autoritária e compensatória. A tutela não emancipa, infantiliza.

Precisamos alterar radicalmente nossos processos de ação junto aos pobres. A opção precisa ser pela emancipação!

Para produzir processos emancipatórios são necessárias, no campo da educação escolar, as seguintes condições:

1 Indicador Nacional de Analfabetismo Funcional - INAF: construído pelo Instituto Paulo Montenegro, ONG Ação Educativa e Ibope. Analfabetismo funcional refere-se às condições de uso das habilidades de leitura e escrita em diferentes situações da vida diária. 
(a) Assegurar co-autoria do aluno, da sala de aula, dos pais e da comunidade. Não se faz por! Mas, sim, com!

(b) Criar rotas de aprendizagem que permitam a crianças, adolescentes e jovens perseguirem e ganharem novas aprendizagens com maior autonomia.

(c) Reconhecer e trabalhar com potências, e não com vulnerabilidades.

(d) Centrar a pauta da escola na oferta de aprendizagem. Os alunos querem oferta de aprendizagens. E quando falamos em aprendizagens é preciso lembrar que vivemos um mundo de muito maior acesso a informações e conhecimentos veiculados pelos meios multimidiáticos. Vivemos hoje possibilidades reais de acesso a conhecimentos e aprendizados compartilhados.

(e) Compreender que a escola é da comunidade e, portanto, não reduzi-la a um equipamento da rede de ensino. A escola tem obrigação de identificar e articular os vários sujeitos e espaços de aprendizagem existentes na comunidade para ampliar e otimizar as oportunidades de aprendizagem para seus alunos.

(f) Assumir que a escola não pode tudo, mas em conjunto aos demais serviços e projetos da comunidade, pode desenvolver ao máximo as possibilidades de aprendizagem do grupo infanto-juvenil de determinado território.

Essas são recomendações que poderíamos chamar de ligeiras no exercício da função social da escola.

Por isso mesmo é necessário situá-las num quadro mais geral da política social que se quer emancipatória.

2 Pensar a política social na sua inteireza. Não mais fatiada em educação, cultura, saúde, assistência social...

(a) A política social em nosso país clama por uma nova arquitetura de gestão pública, fundamentada na lógica da cidadania que promova ações integradoras em torno do cidadão e do local como eixos de um desenvolvimento sustentável.

(b) O cidadão já não quer ser reconhecido como um somatório de necessidades e direitos; deseja atenções integrais (integralizadas). O Estatuto da Criança e do Adolescente é, nesse sentido, uma lei referencial, 
pois anuncia de forma enfática o direito de crianças e adolescentes a uma proteção e desenvolvimento integral.

(c) Políticas e programas desenhados pelo prisma da multissetorialidade, substituindo os tradicionais recortes setoriais e especializações estanques.

(d) O novo modo de pensar o arranjo e gestão da política social derruba a força da setorialização das políticas ditas sociais; de outro, reforça uma nova tendência, a de programas-rede que agregam diversos serviços, projetos, sujeitos e organizações no âmbito do micro território. Não mais ações isoladas.

Por isso mesmo, os serviços na ponta ganham uma margem fundamental de autonomia para produzir respostas assertivas, flexíveis e combinadas, de direito do cidadão e de direito ao desenvolvimento sustentável do território a que pertencem.

\section{Concluindo}

É necessário reforçar que políticas e programas sociais sejam movidos por processos. Processos emancipatórios que processam autonomia. Processos compensatórios ou tutelares processam dependência com pouco impacto na superação da pobreza.

Como buscar a emancipação? Os programas precisam ser movidos por processos de ação que assegurem o desenvolvimento da autonomia. Na pauta de estratégias de construção da cidadania é preciso dar primazia à educação, à ampliação do universo informacional e cultural e à conquista de interlocução política (ganhos de poder).

É nosso velho conhecido o diagnóstico de que as desigualdades sociais produzem uma cisão no acesso às riquezas societárias, ou, ainda, um sistema dual no usufruto de bens e serviços de direitos: para os já incluídos, o transito normal no acesso aos bens e serviços; para os desiguais, um acesso precário ou marginal a bens e serviços.

A desigualdade está tão enraizada em nossa cultura política que, embora defendamos direitos não, sabemos desenvolver cidadania.

Os processos e estratégias na condução de programas sociais articulam intencionalmente utopias, conhecimentos, tecnologias, habilidades e atitudes.

Assim, qualquer programa socioeducacional só ganha eficácia emancipatória quando implementado por meio de um competente trabalho sociopedagógico. É possível afirmar que o trabalho sociopedagógico compõe-se de um conjunto de processos e estratégias de informação, mobilização, advocacy social, organização e participa- 
ção da população acoplado a um conjunto de metas e resultados de desenvolvimento de capacidades básicas. Os processos dão ancoragem e direção aos programas sociais ofertados no combate à pobreza.

$\mathrm{Na}$ essência de um propósito emancipatório e de desenvolvimento da autonomia, está a participação pró-ativa da população alvo. Assim, a pergunta que se faz é exatamente se os programas e instituições se convertem em espaços públicos de vocalização, participação e interlocução política dos cidadãos que os freqüentam. Se são, em si, espaço de expressão e troca de saberes.

Quando a autoria do saber/ação não é compartilhada com o público-alvo, quando o sentido da ação é apropriado apenas pelo técnico, sem espaço para o protagonismo do destinatário, essa deixa de ser relação libertadora.

Assim, mantém-se na ordem do dia a tensão entre duas lógicas distintas na condução de programas e ações sociais púbicas: a lógica da tutela ou compaixão e a lógica dos direitos. Na primeira, continua-se ofertando programas sem compromisso com os resultados. É como se "para pobres ou desiguais, qualquer ação fosse lucro". A prática da tutela é justificada pela falta de crédito na capacidade dos pobres em processarem inclusão. Por isso a prática da tutela põe acento em ações compensatórias, minimizadoras dos males produzidos pela exclusão e pobreza.

Na lógica dos direitos, o fundamento da ação social pública é o próprio direito. Põe acento em estratégias voltadas ao fortalecimento emancipatório (empowerment) e autonomia das populações - alvo das ações públicas. Prioriza a interlocução política destas com a sociedade e Estado, objetivando dar voz e reconhecimento às mesmas. Fortalece vínculos relacionais capazes de assegurar inclusão social. Fortalece as relações entre indivíduos e grupos com suas comunidades. Desenvolve confiança ativa no coletivo e comunidade a que pertencem. Ganham primazia as dimensões ética, estética e comunicativa.

\section{The tutelary way of thinking in the education of the popu- lar groups in Brazil}

Abstract: this article focus on the tutelary way of thinking still rooted in the Brazilian political culture, which causes perpetuation of an education that excludes the poor people.It describes the importance of an emancipating action.

Keywords: Equal education. Social issues. Educational policy. Politics (Brazil). 


\section{La pensé Tutélaire présente dans des groupes éducatifs populaires au Brésil}

Résumé: Cet article s'occupe de la pensée tutelaire enracinée dans la culture politique brasiliénne qui mantient une éducation d'exclusion. Met en evidence le sens et l'importance d'une action émancipatrice.

Mots-clés:Éducation. Culture politique. Questions sociales. Politique (Brésil).

\section{El pensamiento tutelar presente en la educación de los gru- pos populares en Brasil}

Resumen: Este artículo trata del pensamiento tutelar aún arraigado en la cultura política brasileña que mantiene una educación excluyente. Destaca el significado y la importancia de la acción de emancipación.

Palabras-clave: Derechos a educación. Questoes sociais. Politica educacional. Política (Brasil).

\section{Referências}

SAEB 2001: novas perspectivas. (2001). Brasília, DF: Instituto Nacional de Estudos e Pesquisas Educacionais.

Sen, A. (2000). Desenvolvimento como liberdade. São Paulo: Companhia da Letras.

Maria do Carmo Brant de Carvalho, Coordenadora Geral do Centro de Estudos e Pesquisas em Educação, Cultura e Ação Comunitária - Cenpec, doutora em Serviço Social e professora do programa de pós-graduação em Serviço Social da PUC-SP.Endereço eletrônico: rios@cenpec.org.br. 